\title{
Exploring the Influence of a Smartphone App (Young with Diabetes) on Young People's Self-Management: Qualitative Study
}

Gitte Reventlov Husted ${ }^{1}, \mathrm{RN}, \mathrm{MScN}, \mathrm{PhD}$; Janne Weis ${ }^{2}, \mathrm{RN}, \mathrm{MScN}, \mathrm{PhD}$; Grete Teilmann ${ }^{1}, \mathrm{MD}, \mathrm{PhD}$; Pernille Castensøe-Seidenfaden ${ }^{1}, \mathrm{MD}, \mathrm{PhD}$

${ }^{1}$ Pediatric and Adolescent Department, Nordsjællands Hospital, University of Copenhagen, Hillerød, Denmark

${ }^{2}$ Department of Neonatology, Rigshospitalet, University of Copenhagen, Copenhagen, Denmark

\section{Corresponding Author:}

Pernille Castensøe-Seidenfaden, MD, PhD

Pediatric and Adolescent Department

Nordsjællands Hospital

University of Copenhagen

Dyrehavevej 29, 1511

Hillerød, 3400

Denmark

Phone: 4548294650

Fax: 4548293034

Email: pernille.castensoee-seidenfaden@ regionh.dk

\section{Abstract}

Background: Adequate self-management is the cornerstone of preventing type 1 diabetes mellitus (T1DM) complications. However, T1DM self-management is challenging for young people, who often struggle during the transition from childhood to adulthood. The mobile health (mHealth) app Young with Diabetes (YWD) was developed in collaboration with young people to enhance their T1DM self-management during this transition.

Objective: The purpose of this study was to explore the influence of YWD on young people's self-management during a 12-month period.

Methods: A qualitative explorative approach was used, comprising a purposive sample of 20 young people (11 females and 9 males, ages 15 to 23 years, with app use of 3 to 64 days) from 3 pediatric and 3 adult departments. Participants were interviewed individually using a semistructured interview guide. Data were collected from January to March 2017 and analyzed using thematic analysis.

Results: A total of 5 themes were identified: (1) not feeling alone anymore ("we are in this together"); (2) gaining competence by sharing experiences and practical knowledge ("they know what they are talking about"); (3) feeling safer ("it's just a click away"); (4) breaking the ice by starting to share thoughts and feelings and asking for help ("it is an outstretched hand"); and (5) lack of motivating factors ("done with the app"). Young people reported that YWD promoted self-management by peer-to-peer social support, exchanging messages with health care providers, and sharing YWD with parents. Participants recommended YWD as a supplement to self-management for newly diagnosed young people with T1DM and suggested improvements in app content and functionality.

Conclusions: The mHealth app YWD has the potential to support self-management. In particular, peer-to-peer support reduced feelings of loneliness and helped young people to gain knowledge and skills for managing T1DM. A need exists for alternative ways to train health care providers in using YWD and to support collaboration between young people and their parents to further improve young people's self-management of T1DM.

(JMIR Mhealth Uhealth 2018;6(2):e43) doi: 10.2196/mhealth.8876

\section{KEYWORDS}

mHealth; diabetes mellitus, type 1; youth; self-management; qualitative research 


\section{Introduction}

\section{Background}

Type 1 diabetes mellitus (T1DM) is a demanding disease for young people, who struggle to learn to self-manage their condition during the transition from childhood to adulthood $[1,2]$. As young people gradually become more independent, they are expected to take on responsibility for T1DM management that includes administering daily insulin, measuring blood sugars, and counting carbohydrates to meet the recommended glycemic control target [3]. However, new lifestyles and physical, cognitive, and social changes challenge daily T1DM self-management routines [4]. This often results in impaired glycemic control [5,6], increased risk of acute complications [7], and early onset of long-term complications $[8,9]$. In addition, young people with T1DM often skip clinical visits, endangering their current and future health [5]. Flexible engagement and continuity with health care providers and ongoing support from parents are still needed [10,11]. However, current routine care $[5,6]$ does not seem to meet young people's need for T1DM self-management support [12-14].

Mobile health (mHealth) apps seem to be suitable tools for engaging young people in self-management by providing information and optimizing interaction with health care providers and parents [15-19]. However, most mHealth studies to date have been conducted among adults. A review of mHealth apps identified 2 apps only that support T1DM self-management among adolescents [20]. Cafazzo et al showed an improvement in the frequency of blood glucose monitoring when testing an app to facilitate feedback on automated blood glucose readings [21], whereas Frøisland et al demonstrated an increased understanding of applied knowledge when testing the combination of a picture-based diabetes diary and a text messaging service [22]. Finally, a recent study by Holtz and colleagues reported that a patient-centered mHealth app for adolescents with T1DM and their parents seemed to enhance their collaboration [18]. In conclusion, the use of apps appears to have the potential to improve current patterns of providing self-management support [19]; however, there is a lack of evaluation studies focusing on the effect of mHealth apps on young people's management of their long-term conditions.

\section{Young With Diabetes App}

The Young with Diabetes (YWD) mHealth app was developed in a mixed-methods design based on a participatory and iterative approach [23] in collaboration with young people with T1DM, parents, health care providers, a team of health researchers, and information technology (IT) consultants. The goal of YWD was to provide a supplemental tool to support young people in developing T1DM self-management knowledge and skills during the transition from childhood to adulthood.

YWD is based on a family-centered approach [24] as recommended by transition guidelines $[3,25,26]$ to improve self-management [1], defined as "an active, daily and flexible process in which youths and their parents share responsibility and decision-making for achieving disease control, health, and well-being through a range of illness-related activities" (p 92) [27]. Acquiring self-management in living with T1DM is a gradual process. 
Figure 1. The eight main functions of the Young with Diabetes app. T1DM: type 1 diabetes mellitus.

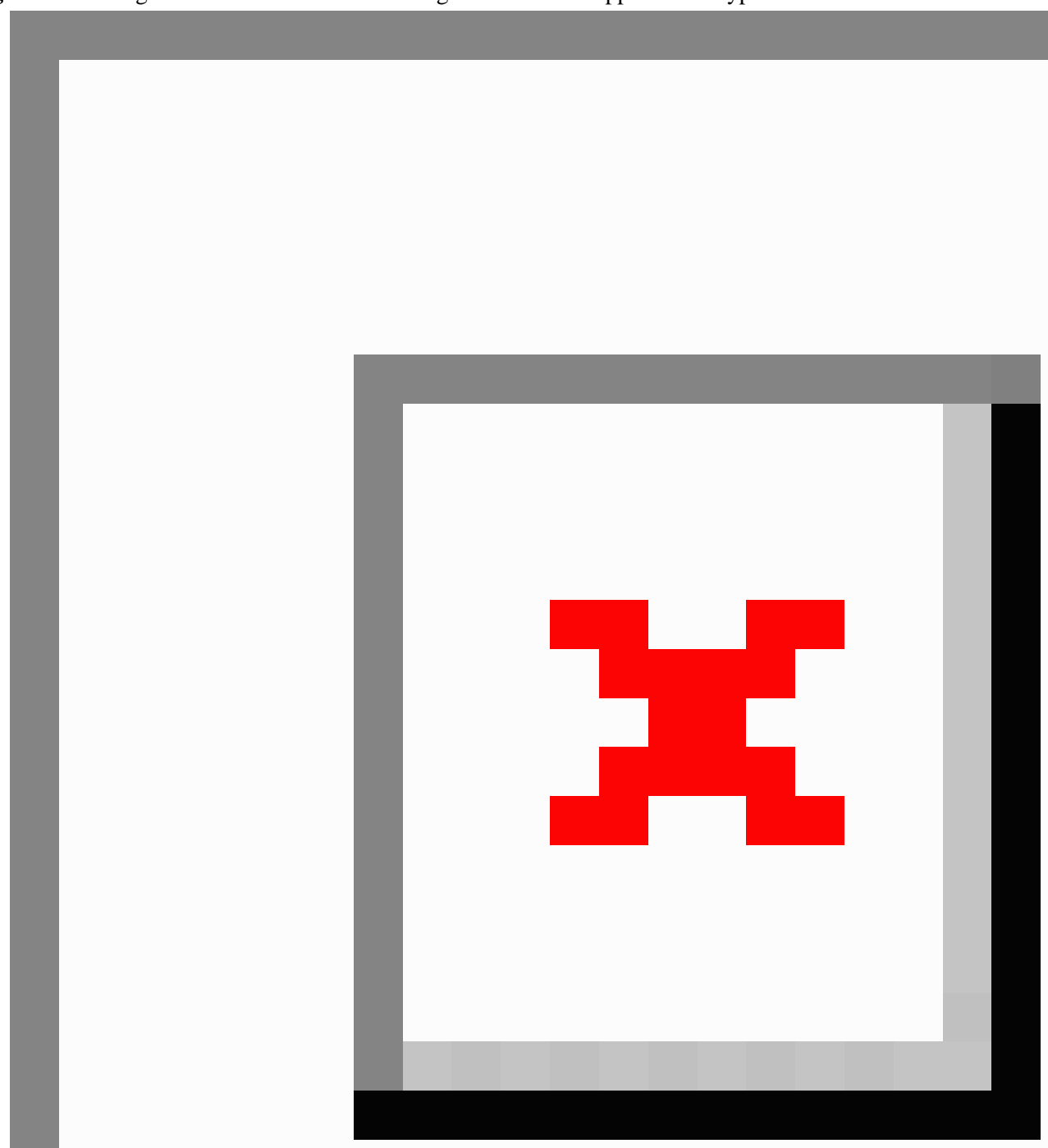

YWD comprises 8 main functions (Figure 1): (1) My Page enables users to contact their health care provider and write notes, (2) My Department contains information about diabetes outpatient clinics, (3) Chat Room offers peer-to-peer interaction, (4) Carbohydrate Counting, (5) Information about T1DM, (6) Tips Package provides daily T1DM tips, (7) To Parents provides information for parents on how to support their teen, and (8) Reminder. Further details are provided elsewhere [23]. The YWD content did not change during the test period.

Young people, their parents, and health care providers received the same version of YWD, except the Chat Room that was only available for young people. Anonymity in the Chat Room was encouraged with the use of nicknames.
The aim of this study was to explore YWD's influence on young people's self-management during a 12-month period.

\section{Methods}

\section{Design and Participants}

A qualitative exploratory interview study was embedded in a 12-month randomized controlled trial (RCT) testing the effect of YWD on young people's self-management skills. A purposive sample [28] of young people with T1DM who had completed the RCT study in the intervention group was recruited from January to the end of March 2017. They were invited to participate by the last author at the final data collection visit. 
Young people and their parents were randomized to the intervention group (YWD, $n=76$ ) or control group $(n=75)$, and participants in the YWD group downloaded the app on their mobile phone or tablet. PC-S provided an initial $10 \mathrm{~min}$ introduction of the app to the participant in person or by telephone. Participants were encouraged to use YWD between clinical visits and in collaboration with parents and health care providers. No prompts or reminders triggered app use. All young people had a mobile phone.

Health care providers were encouraged to use the app in the outpatient clinic. YWD-trained diabetes team members, including physicians, nurses, and dieticians $(n=39)$ with at least 1 year of diabetes outpatient clinic experience, provided the YWD intervention as part of usual practice. Monthly face-to-face sessions were offered to refresh the use of YWD, and a telephone hotline was available in case of technical issues.

\section{Data Collection}

Individual interviews were conducted between January and March 2017 from 1 to 3 weeks after the RCT was completed. The interviews were conducted by GRH (an experienced female researcher who did not know the participants). GRH interviewed participants independently of their parents in their homes $(n=19)$ or at school $(n=1)$, using a semistructured interview guide (Multimedia Appendix 1) that included exploring individual reasons for variations in outcomes. The interview guide was inspired by an empowerment approach as defined by Anderson and Funnell [29]. The process of empowerment is defined as: “...the discovery and development of one's inborn capacity to be responsible for one's own life. People are empowered when they have enough knowledge to make rational decisions, control, resources to implement their decisions and experience to evaluate the effectiveness of their actions" (p 11) [29]. Interviews lasted for 35-60 min and were digitally recorded, transcribed verbatim, and checked for accuracy [30] by the first author. Transcripts were uploaded to NVivo software (QSR International version 11, QSR International Pty Ltd, Doncaster Victoria, Australia) to organize data and support the analysis.

Outcomes measures for the RCT included posttrial hemoglobin $\mathrm{A}_{1 \mathrm{c}}\left(\mathrm{HbA}_{1 \mathrm{c}}\right)$ levels (primary outcome) and scores on 3 psychometric scales (secondary outcome): Perceived Competence in Diabetes (PCD) [31], Health Care Climate Questionnaire (HCCQ) [31], and Problem Areas in Diabetes (PAID-20) [32]. These scores, along with baseline characteristics, were used to characterize interview participants.

The study was approved by the Danish Data Protection Agency (no. 04015 NOH-2015-031) and performed in accordance with the ethical recommendations of the Helsinki Declaration. Ethical approval of interview studies by Research Ethics Committee is not necessary in Denmark (no. 15000468). An information leaflet to participants stated that data would be treated confidentially and anonymously and that they could withdraw from the study without consequences for their treatment and care at the outpatient clinic. Written consent was obtained from all participants and from parents if participants were younger than 18 years. After each interview, GRH spent some time with participants to make sure they felt comfortable having shared their experiences with app use.

\section{Data Analysis}

Data were analyzed using a 6-phase thematic analysis provided by Braun and Clarke [33]: (1) familiarization with the data, (2) generating initial codes, (3) interpreting and sorting codes into themes, (4) reviewing themes for coherent patterns, (5) defining and naming the themes, and (6) producing the report [33]. GRH analyzed all interviews, generating initial codes and potential themes before discussing them with coauthors.

Subsequently, GRH and JW refined the categorization of codes into potential themes. Initially, this was an inductive process, followed by applying a more deductive approach during steps 3 and 4 to explore whether the app content and functions met young people's needs [1,5]. Throughout all phases, constant checking of data extracts, codes, and themes against each other and the entire dataset was performed.

Credibility was addressed by researcher triangulation throughout the analysis, with GRH, PC-S, and GT having experience with T1DM and GRH, JW, and PC-S having experience with qualitative research. Feedback from the researchers was discussed at meetings until consensus was reached. Bias was diminished by having a coresearcher, who had not participated in the development of the app, to handle the analysis. Transferability was ensured by offering thick descriptions, dependability by providing quotes from informants, and confirmability by thoroughly describing the processes of sampling, data collection, and analysis [34].

\section{Results}

In total, 22 young people were invited to participate; 2 (1 female) declined due to exams or illness. The final sample comprised 20 young people (11 females and 9 males; age range, $15-23$ years). They differed in app use and in the primary and secondary outcome measures (Tables 1 and 2).

Although young people still found daily self-care tasks difficult, YWD was experienced as a valuable tool to support T1DM self-care:

\section{You damn need to do something [to self-manage T1DM]...but it [YWD] has helped me to do some of the daily work. [20-year-old female, ID17]}

This was identified through 5 themes: (1) not feeling alone anymore ("we are in this together"); (2) gaining competence by sharing experiences and practical knowledge ("they know what they are talking about"); (3) feeling safer ("it's just a click away"); (4) breaking the ice by starting to share thoughts and feelings and asking for help ("it is an outstretched hand"); and (5) lack of motivating factors ("done with the app"). In the following section, the findings are detailed.

\section{Theme 1: Not Feeling Alone Living With T1DM Anymore- "We Are in This Together"}

The Chat Room proved to be the most important function of YWD. Finding peers who faced the same challenges in T1DM self-management was enlightening for all interview participants; they felt that:

...we are in this together. [20-year-old female, ID1] 
Feelings of loneliness were relieved when young people became aware that their struggles were familiar issues among their peers. The possibility of contact with peers made their current challenges and worries easier to bear, as did knowing that they were not alone in having these burdens. Some participants had never met other young people living with T1DM, as illustrated here by a male:
I have gained a slightly better understanding, because before I had the app it was a little difficult to realize how others my age felt because there is no one at my school...that has diabetes...I think it is good to know that I am not the only one that has these problems or thinks about the same things, like the future with diabetes and all that. [18-year-old male, ID15]

Table 1. Participant characteristics $(n=20)$.

\begin{tabular}{|c|c|}
\hline Characteristic & Value \\
\hline \multicolumn{2}{|l|}{ Gender, n (\%) } \\
\hline Female & $11(55)$ \\
\hline \multicolumn{2}{|l|}{ Age in years, mean (SD, range) } \\
\hline At baseline & $18(2.60,14-22)$ \\
\hline Diabetes duration at baseline in years, mean ( $\mathrm{SD}$, range) & $9(4.62,3-18)$ \\
\hline \multicolumn{2}{|l|}{ Insulin regimen, $\mathrm{n}(\%)$} \\
\hline Multiple daily injections of insulin & $11(55)$ \\
\hline Pump & $9(45)$ \\
\hline Participant lives with both parents & $9(45)$ \\
\hline Divorced & $10(50)$ \\
\hline At least 1 participating parent & $13(65)^{\mathrm{a}}$ \\
\hline \multicolumn{2}{|l|}{ Pediatric site, $\mathrm{n}(\%)$} \\
\hline Pediatric and Adolescent Department, Nordsjællands Hospital, Hillerød & $4(20)$ \\
\hline Pediatric and Adolescent Department, Herlev & $5(25)$ \\
\hline Pediatric Department, Roskilde & $1(5)$ \\
\hline \multicolumn{2}{|l|}{ Adult site, n (\%) } \\
\hline Department of Cardiology, Nephrology and Endocrinology, Nordsjællands Hospital, Hillerød & $2(10)$ \\
\hline Transfer to adult care, $\mathrm{n}(\%)$ & $2(10)$ \\
\hline Active app days, mean (SD, range) & $19(15.87,3-64)$ \\
\hline
\end{tabular}

${ }^{\mathrm{a}} \operatorname{Mother}(\mathrm{n}=8)$, father $(\mathrm{n}=1)$, both mother and father $(\mathrm{n}=4)$. 
Table 2. Participant scores at baseline and at the end of the 12-month trial $(n=20)$.

\begin{tabular}{llll}
\hline Outcome measures & Range of possible scores & Baseline, mean (SD) & 12 months, mean (SD) \\
\hline $\mathrm{HbA}_{1 \mathrm{c}}{ }^{\mathrm{a}}$ & - & $83(20)$ & $27(8)$ \\
$\mathrm{PCD}^{\mathrm{b}}$ & $5-35$ & $27(19)$ \\
PAID $^{\mathrm{c}}$ & $0-100$ & $21)$ & $28(19)$ \\
$\mathrm{HCCQ}^{\mathrm{d}}$ & $5-35$ & $28(7)$ & $29(6)$ \\
\hline
\end{tabular}

${ }^{\mathrm{a}} \mathrm{HbA}_{1 \mathrm{c}}$ : hemoglobin $\mathrm{A}_{1 \mathrm{c}}, \mathrm{mmol} / \mathrm{mol}$; assesses blood sugar control.

${ }^{b}$ PCD: Perceived Competence in Diabetes; assesses patients' experience of feeling able to successfully manage diabetes; higher scores represent greater perceived competence.

${ }^{\mathrm{c}}$ PAID: Problem Areas in Diabetes; assesses diabetes-related distress; higher scores indicate greater emotional distress, and a score $\geq 30$ indicates elevated distress.

${ }^{\mathrm{d}}$ HCCQ: Health Care Climate Questionnaire; assesses the degree to which patients perceived their health care providers as supporting their autonomy; higher scores indicate a high level of perceived support for autonomy.

The possibility of participating in chats or simply observing chat comments helped young people acknowledge that it was not always easy to self-manage T1DM. They realized that peers were familiar with their concerns, frustrations, and challenges, which helped reduce feelings of loneliness, as expressed by a female:

[I]t is good to know that you are not the only one with it...of course you have the support from your family and your friends, who say that you will get through it...but hearing it from someone who also has it and knows what you are going through and...to have others you can talk to, that is very, very nice. [18-year-old female, ID14]

Feeling like everyone else and "being normal" (16-year-old female, ID9) occurred when young people were in the Chat Room. By reflecting on their peers' ways of living, young people experienced normalization of T1DM into everyday life. This contrasted with the feeling of being different that often arose when spending time with friends without T1DM:

[O]ften you feel that you are walking around in your own little world, because you are surrounded by people that don't have diabetes. [18-year-old female, ID14]

The Chat Room provided a safe, closed space where a spirit of companionship arose even though the young people did not know each other. A female described the experience:

[O]ften when you are at school, you are reminded that you have diabetes...But when you are in that diabetes chat room, then you are among others, and it is like the diabetes things are something that you have in common with the others. [18-year-old female, ID14]

\section{Theme 2: Gaining Competence by Sharing Experiences and Practical Knowledge-“"They Know What They Are Talking About"}

Young people shared T1DM experiences in the Chat Room, which helped them gain new knowledge and skills for managing their disease. They became aware of the difference between advice and information they received at outpatient clinic visits and the insights and real-life knowledge they received in the Chat Room:

\section{...they know what they are talking about. [22-year-old male, ID3]}

They experienced health care providers as being unable to provide the person-specific information they sought. On the contrary, health care providers often discussed T1DM in general ways, for example, by looking at blood sugar curves trying to figure out the cause of fluctuations. The young people found that sharing experiences with peers provided valuable and reliable person-specific information, such as how to manage hypoglycemia or deal with challenges when traveling. This knowledge improved their self-management competencies, as described by a male:

[O]ne way is that a physician tells you how to do it, another thing is when the ones that have [T1DM], tell what they do to make their blood sugar levels drop or what they do when they travel, so that has helped me quite a lot. [18-year-old male, ID15]

Young people became confident about trying out new ways of handling T1DM. They exchanged tips and tricks, such as precautions for driving, how to regulate blood sugar in relation to sports, and how to use the different functions of the insulin pump around meals to avoid fluctuating blood sugars.

There are people who have solutions to problems that you might not be able to find yourself. [16-year-old male, ID13]

Easy access to the Chat Room provided young people with opportunities to immediately change self-care practices. As a female described:

There was one person who wrote that she used the basal [rate] in the pump... and I didn't know that you could turn up the basal, then she wrote how to do it...that has helped me a lot, now it [the blood sugar level] doesn't fluctuate as much. [19-year-old female, ID6]

Young people gained practical knowledge that supported their participation in social life, such as going out with friends, while still feeling confident about taking care of their T1DM. 
Exchanging experiences in the Chat Room provided them with real-life scenarios of risky situations, such as drinking alcohol. They did not receive this type of information from their health care providers. From their peers, they received concrete instructions about how to act and cope, as described by a female:

\section{...it has also helped me a lot with what to do if things go wrong when I drink and am at a party... [18-year-old female, ID14]}

Most young people had not used the Information about...section, often because they felt they knew everything about T1DM after having been diagnosed years previously:

Maybe sometimes it is just the words, "Information About," where I think I don't need to read that.

[20-year-old female, ID17]

Therefore, they did not consider the informational part of the app as an option for obtaining advice about how to self-manage different situations in real-life contexts. However, they were convinced that the information function of YWD would be very useful for young people newly diagnosed with T1DM. As a male put it:

\section{...The category "Information About" would be real smart for new diabetics who don't have any idea as to how the different things affect your body. [17-year-old male, ID18]}

\section{Theme 3: Feeling Safer Having the App-“It's Just a Click Away"}

Young people felt safer living with T1DM knowing that all the information they needed about their disease was available in YWD. This gave them a sense of freedom and peace:

\section{It has been a relief for me that all my diabetes things are gathered in one location. [18-year-old female, ID14]}

Before using the app, they had often had difficulty maintaining an overall perspective on their T1DM while taking care of school, work, and youth life. Ready access to information and knowledge made self-management easier:

\section{It's just a click away. [20-year-old female, ID5]}

For instance, some young people used links in the app to figure out how to count carbohydrates, some gained new perspectives by watching video self-portraits, and some reached out to peers or health care providers. YWD functioned as a kind of "back up" (16-year-old male, ID13) in almost all aspects of life with T1DM from minor concerns to acute issues. Young people viewed the app as a lifeline and felt safe just having it, as described by a female:

...then it is more reassuring with the app...let us say you have a situation, and then you can quickly...sit and look it up. [20-year-old female, ID1]

A few young people benefited from writing personal notes in the My Page function to organize their life with T1DM. Before using the app, they had expended a great deal of energy figuring out how their blood sugar responded to activities and food intake. By making notes about their reactions during different activities and in various circumstances, they gradually developed a personal guide to rely on in similar situations. This app function provided a parking lot for speculation and worry, helping ease their minds. As a female explained:

\section{I have gotten a better perspective on it, so I don't have so many different thoughts... and I have gotten it all gathered so I can access it directly and see, that is what I did the last time and create my own guides to what I need to do, so that has helped me a lot. [18-year-old female, ID14]}

Young people appreciated that the app's informational sections were easy to understand and focused on the most important aspects of T1DM. They had greater confidence in the information presented by YWD than in information they had previously located online. This gave them a sense of safety, as expressed by a male:

\section{Information about...," that is professionals that have written that, it is not someone off some Google home page...so that makes it a lot more reassuring to have this app. [17-year-old male, ID13]}

\section{Theme 4: Breaking the Ice by Starting to Share Thoughts and Feelings and Asking for Help- "It Is an Outstretched Hand"}

For some young people, YWD became a way to break the ice with their health care providers and parents. It supported them in sharing thoughts and feelings about their challenges of living with T1DM and asking for help.

Young people found that contacting health care providers through YWD was very informal, which facilitated writing messages:

\section{I communicate with my nurse in a completely different way -I can be much more honest. [20-year-old female, ID17]}

Young people primarily wrote about practical things such as scheduling appointments or new prescriptions. They emphasized that health care providers did not introduce YWD during outpatient clinic visits or only referred to it superficially, such as by asking whether they had used the app. Young people had the impression that the app was not meant for collaboration. However, YWD made a profound difference in the few instances in which young people used it in collaboration with health care providers. For example, they used it to ask for help to lose weight or help to manage an eating disorder, topics that had not been discussed during clinic visits. A female described it this way:

I have had difficulties with my eating disorder, and that has not been something I have told my practitioners, so the app gave me an opportunity...to write them, because it was hard for me to say, either over the phone or face-to-face. [23-year-old female, ID10]

Other young people used the "Unfinished sentences" in the My Page function as a way to break the ice and address unspoken difficulties in living with T1DM. They felt that doing so made it possible to talk openly about their thoughts and feelings: 
The thing that I am worst at, regarding my diabetes..." that is a very accurate sentence, because it is like taboo. [20-year-old female, ID17]

By sharing their thoughts and feelings with health care providers, young people suddenly experienced more continuity in those relationships. This promoted sharing successes and failures and receiving ongoing support, which not had been possible before.

It motivated young people to improve their self-management because health care providers immediately responded to their actions. A female explained it this way:

The thing about how many blood sugar levels I have measured in so and so many days, that I would never have told her, but she sees the progress and tells me about it and praises me for it and that would not have happened without the app. [20-year-old female, ID17]

YWD also became a way for young people to break the ice and start to share thoughts and feelings about the challenges of living with T1DM with their parents and to ask for help when needed. Some young people and their parents looked at the video self-portraits or at posts in the Chat Room, competed in the Carbohydrate Counting Quiz, or looked at the information sections separately or together. They then began to talk about topics that previously had been difficult to discuss openly, as in the example of a male who had talked about sex with his father for the first time while looking at the app together:

$[M]$ e and my dad, we talked about the issue of having sex with diabetes...that is probably not something I would have thought about normally-if there is a difference there...so because of the app we actually talked about some stuff. [17-year-old male, ID18]

Young people described their parents as gaining a deeper and more nuanced perspective on the difficulties they faced in trying to self-manage T1DM. This changed the way parents and young people interacted about their self-management. Young people described their parents as seeming more eager to provide appropriate autonomy support, rather than admonishing or comforting them. As a girl describes:

We talk about it in a different way, because they are informed about it, and they have asked... "Have you had it like that...?" and I have said "I think, like all the others, that it is a shitty thing to have" ...then they have said: "If there is something we can do [as opposed to everything will be all right], we would like to help." They somehow better understand how it works in our minds...how we feel about our diabetes. [18-year-old female, ID14]

Young people felt that their parents started to show greater confidence in them, and they had the impression that their parents suddenly took their situation and frustrations more seriously. In some cases, this led to changes in their parents' point of view, including relaxing rules as they became more confident that the young person could handle, for instance, alcohol. A boy stated the following:

\begin{abstract}
Here in the beginning of last year, my parents wouldn't allow me to drink, and now I have just gotten permission since we looked at the app together, there was a chat concerning alcohol and that has helped us a lot. [15-year-old male, ID20]
\end{abstract}

\section{Theme 5: Lack of Motivating Factors_- Done With the App"}

Despite the fact that young people appreciated YWD, some also expressed being "done with the app" after the first few months because no new information, quizzes, or video self-portraits were added during the trial. A male said:

It would be nice if it [YWD] was updated...it's like Wikipedia, when you have read it, then you have read it, new knowledge won't suddenly appear. [17-year-old male, ID18]

Moreover, they noticed decreased activity in the Chat Room, which reduced their motivation for keeping the app. A male described the lack of motivating factors:

There aren't enough who write, so it is kind of like...it is hard to see where the app is supposed to take us, when there aren't enough who use it to answer and write. [22-year-old male, ID3]

However, young people wanted to keep YWD, except for 3 male participants, aged 20 to 22 years, who no longer wanted it due to the static content. All participants had many suggestions for improvements to content and functionality to ensure more activity and make YWD more useful (Table 3). 
Table 3. Suggestions for improving Young with Diabetes content and functionality. T1DM: type 1 diabetes mellitus.

\begin{tabular}{|c|c|}
\hline Main function & Suggestions for improvements \\
\hline \multirow[t]{4}{*}{ My Page } & Share the notes, diary, and messages with parents \\
\hline & Visualize blood glucose readings in a graph and compare the readings with recommendations \\
\hline & Set a blood glucose level goal and receive motivating feedback notifications \\
\hline & Access your medical record, such as information about treatment and hemoglobin $\mathrm{A}_{1 \mathrm{c}}$ \\
\hline My Department & Automatic information from the hospital database about your health care provider, department, and phone number \\
\hline \multirow[t]{6}{*}{ Chat Room } & Add a parent chat room \\
\hline & Add closed chat rooms \\
\hline & Add invitations to events \\
\hline & Create your own chat themes and change the order of the predefined themes \\
\hline & Include the opportunity to chat with a diabetes physician \\
\hline & Create a profile similar to Instagram \\
\hline Carbohydrate Counting & Include specific amount of carbohydrates \\
\hline \multirow[t]{5}{*}{ Information about T1DM } & Continuously updated information, such as the newest research in T1DM \\
\hline & Detailed information about treatment options, such as photos of devices \\
\hline & Include quizzes on T1DM topics with varying levels. Upload new quizzes regularly \\
\hline & Add an introduction to the video self-portraits and place the video self-portraits in front with a more obvious play button \\
\hline & Improve the overview and shortcuts to the most frequently used T1DM apps \\
\hline To Parents & Include information about what it is like to be a parent of a young person with T1DM \\
\hline \multirow[t]{6}{*}{ Other suggestions } & Quick introduction to Young with Diabetes by a short animation describing content and functionality \\
\hline & Customization, such as choosing the background, the start page, and placing the favorite sections in front \\
\hline & Improve the intuitive interface by adding more visual icons and small information boxes \\
\hline & Reduce scrolling of long text sections and reduce the number of "clicks." Add shortcut options \\
\hline & Add a narrator button to read the text for people with reading difficulties \\
\hline & Fingerprint login \\
\hline
\end{tabular}

\section{Discussion}

\section{Principal Findings}

This qualitative study provides insight into the mHealth app YWD as a motivating factor and a supplemental tool to self-manage T1DM. In particular, young people experienced interactions in the Chat Room, exchanging messages with health care providers, and looking at the YWD with parents as useful features. Our findings show the importance of helping young people communicate with like-minded peers to share feelings, practical knowledge, and experiences. In addition, the findings indicate that YWD is a promising supportive tool to change communication patterns between young people and health care providers during and between outpatient clinic visits and between young people and their parents. Finally, YWD could be a tool for health care providers to address sensitive topics in outpatient clinic visits. However, improvements are also needed to maintain young people's motivation for self-management.

\section{Comparison With Prior Studies}

The Chat Room was found to be the most important part of the app, providing an online community for young people struggling with the same feelings, thoughts, and practical issues related to
T1DM self-management. Young people felt they received support for self-managing specific diabetes situations and experienced diminished feelings of loneliness. Previous research has identified this kind of interaction as diabetes-specific social support [35], which is associated with reduced loneliness in living with T1DM [36]. Social support organized by health care providers as a kind of peer-to-peer support [37] has proven effective in preventing loneliness [38]. However, the literature on diabetes-specific peer support addresses a wide range of peer interactions and interventions [39,40], and the evidence is insufficient to determine the types of peer interactions, elements, and interventions most applicable to young people with T1DM [39]. YWD seems to have the potential to reduce loneliness, as compared with traditional outpatient clinical visits. Our findings emphasize that young people need help to connect with peers to share their experiences in a way that they cannot with parents, health care providers, and other social networks, as identified by Mayer et al [41].

In addition, untreated loneliness is known to contribute to diabetes distress [36,42]. Diabetes distress is high among young people emerging into adulthood [43]. In our study, young people experienced a slight increase in diabetes distress (PAID-20) scores (Table 2). The lack of effect on diabetes distress in our 
study could be explained by decreasing activity in the Chat Room during the trial period. Another potential explanation is that YWD alone does not provide sufficient support for young people with T1DM. Finally, it could be a result of the researchers bringing attention to the feelings of distress, supporting participants in identifying and reporting these feelings.

It is well known that health care providers play a significant role in supporting young people's self-management [44]. However, not all health care providers feel confident using mHealth apps [45], and some may feel uncomfortable engaging with young people through technology $[46,47]$. This may explain why some young people perceived little interest from their health care providers in using the app collaboratively. Overall, YWD could not overcome barriers to frank discussions about sensitive topics, such as sex and alcohol, with which young people often struggle [38]. These topics should be addressed regularly in clinic visits [1]. However, the slight increase in HCCQ scores (Table 2) indicate that YWD may have the potential to complement health care providers' traditional self-management support when used as an ongoing autonomous support in collaboration with the young people. In addition, YWD was able to slightly increase young people's perceived competences in diabetes self-management identified by the PCD scores (Table 2).

Health care providers' training in how to use YWD was very brief, lasting a single hour. This may not have been sufficient to help them feel confident in using the app in collaboration with young people and their parents [23]. Adaption and adoption of new technology require serious implementation work, including developing health care providers' competence at performing new tasks and using the technology as intended [48]. Our study demonstrates that a critical need exists for guidelines on how to optimally train health care providers to use self-management apps as currently recommended [3,25,26].

Interestingly, we found that YWD use often changed interaction patterns between young people and their parents. The app created a platform for young people and parents to approach each other in a more constructive way and enable them to talk about sensitive topics by sharing video self-portraits or posts in the Chat Room or looking at the To Parents section. Parents often face challenges when trying to support their child in achieving self-management $[18,49]$. New ways of facilitating interactions that engage parents and young people during the transition from childhood to adulthood are needed [50,51]. YWD seems to have the potential to complement this process, but methods for encouraging collaborative use of mHealth apps by young people and their parents are needed; only 13 of 20 young people used YWD with their parents (Table 1). However, our findings suggest that combining an online space for exchanging peer support with support from health care providers and parents seems to facilitate more successful self-management, as also identified by Kowitt et al [52].

\section{Implications}

The findings highlight the importance of addressing communication about illness in any patients with long-term conditions by focusing on improving peer-to-peer support as well as supporting the digital communication with health care providers. However, there is a need to focus on health care providers' competence at using mHealth apps. Given the many available mHealth apps, it may be worthwhile to introduce a course during health education programs, such as in medical and nursing schools, focusing on how to use technology collaboratively with patients. This is supported by a recent study [53] in which medical students reported improved understanding of the involved issues and procedures and greater confidence in conducting a telehealth consultation after a course in telehealth skills [53].

In addition, YWD may be a valuable tool for people with newly diagnosed T1DM as recommended by participants in the study. The informational functions of the app may be most useful at an early stage of the disease. We intend to incorporate young people's feedback and suggestions for improvements in content and functionality (Table 3 ) before testing YWD in a group of participants with newly diagnosed T1DM. Because the age at diagnosis of T1DM may be different compared with participants' age in this study, further revision would be of interest to meet the needs of younger participants.

YWD may have the potential to provide a generic model for supporting young people with other chronic conditions and their parents and helping health care providers to engage with young people in ways that provide ongoing support. Despite disease-specific differences, young people with chronic conditions and their parents share many commonalities [16].

\section{Strengths and Limitations}

One of the strengths of our study is the recruitment of participants with a variety of app use, age, gender, T1DM duration, affiliation with diabetes departments, and outcome measures. We consider this population as representative of the entire study group. In addition, patient-centered methods were used to assess YWD. Furthermore, the study used a rigorous qualitative methodology (thematic analysis), as described by Braun and Clarke [33], to provide rich and detailed data, rendering the freedom of combining an inductive and a deductive analysis to identify patterns within data. A limitation is the short-term nature of the study (app use range 3-64 days) and the varying levels of health care provider collaboration. Furthermore, we did not report parents' and health care providers' perspectives on using YWD and its impact on young people's self-management. Currently, parents' and health care providers' perspectives are being explored in questionnaires and focus group interviews, respectively, to make a more informed case about the implications of YWD on all groups of users.

\section{Conclusions}

The YWD app appeared to be a motivating factor in young people's self-management of T1DM. In particular, peer-to-peer support, exchanging messages with health care providers, and looking at the YWD with parents were useful in supporting self-management. YWD changed communication patterns between young people, health care providers, and parents and provided young people with ongoing support. YWD is not effective as a stand-alone intervention, but it seems to have the 
potential to help young people, parents, and health care providers optimize T1DM self-management. A need exists to refine YWD according to users' suggestions, to optimize and standardize health care providers' use of YWD, and to further investigate how the app can be used collaboratively by young people, their parents, and health care providers.

\section{Acknowledgments}

The authors would like to specially thank the young people who participated in this study for generously sharing their experiences, thoughts, and perspectives on using YWD. The authors also thank professor Finn Kensing, Department of Computer Science, University of Copenhagen, Denmark; Eva Hommel, Steno Diabetes Center, Copenhagen, Denmark; and Birthe Olsen, Pediatric and Adolescent Department, Herlev Hospital, University of Copenhagen, Denmark, for their assistance with the development of YWD. The study was funded by Danish Agency for Digitisation, Centre for Telemedicine in the Capital Region of Denmark, and a Research Grant from Nordsjællands Hospital, Hillerød.

\section{Conflicts of Interest}

YWD was developed in cooperation with the IT enterprise Mobile Fitness A/S and the project group (including GRH, GT, and PCS). The project group owns the national rights.

\section{Multimedia Appendix 1}

Interview guide.

[PDF File (Adobe PDF File), 58KB-Multimedia Appendix 1]

\section{References}

1. Castensøe-Seidenfaden P, Teilmann G, Kensing F, Hommel E, Olsen BS, Husted GR. Isolated thoughts and feelings and unsolved concerns: adolescents' and parents' perspectives on living with type 1 diabetes - a qualitative study using visual storytelling. J Clin Nurs 2016 Nov 16;26(19-20):318-330. [doi: 10.1111/jocn.13649] [Medline: 27865017]

2. Crowley R, Wolfe I, Lock K, McKee M. Improving the transition between paediatric and adult healthcare: a systematic review. Arch Dis Child 2011;96(6):548-553. [Medline: 21388969]

3. National Institute for Health and Care Excellence. NICE. Transition From Children's to Adults' Services for Young People Using Health or Social Services URL: https://www.nice.org.uk/guidance/ng43 [accessed 2018-01-15] [WebCite Cache ID 6wURxG6Eo]

4. Suris J, Michaud P, Viner R. The adolescent with a chronic condition. Part I: developmental issues. Arch Dis Child 2004 Oct;89(10):938-942 [FREE Full text] [doi: 10.1136/adc.2003.045369] [Medline: 15383438 ]

5. Castensøe-Seidenfaden P, Jensen AK, Smedegaard H, Hommel E, Husted GR, Pedersen-Bjergaard U, et al. Clinical, behavioural and social indicators for poor glycaemic control around the time of transfer to adult care: a longitudinal study of 126 young people with diabetes. Diabet Med 2017 May;34(5):667-675. [doi: 10.1111/dme.13318] [Medline: 28099760]

6. Petitti DB, Klingensmith GJ, Bell RA, Andrews JS, Dabelea D, Imperatore G, et al. Glycemic control in youth with diabetes: the SEARCH for diabetes in Youth Study. J Pediatr 2009 Nov;155(5):668-72.e1 [FREE Full text] [doi: 10.1016/j.jpeds.2009.05.025] [Medline: 19643434]

7. Nakhla M, Daneman D, To T, Paradis G, Guttmann A. Transition to adult care for youths with diabetes mellitus: findings from a Universal Health Care System. Pediatrics 2009 Dec;124(6):e1134-e1141. [doi: 10.1542/peds.2009-0041] [Medline: 19933731]

8. Bryden KS, Dunger DB, Mayou RA, Peveler RC, Neil HA. Poor prognosis of young adults with type 1 diabetes: a longitudinal study. Diabetes Care 2003 Apr;26(4):1052-1057. [Medline: 12663572]

9. Wills CJ, Scott A, Swift PG, Davies MJ, Mackie AD, Mansell P. Retrospective review of care and outcomes in young adults with type 1 diabetes. Br Med J 2003 Aug 02;327(7409):260-261 [FREE Full text] [doi: 10.1136/bmj.327.7409.260] [Medline: 12896937]

10. Husted GR, Esbensen BA, Hommel E, Thorsteinsson B, Zoffmann V. Adolescents developing life skills for managing type 1 diabetes: a qualitative, realistic evaluation of a guided self-determination-youth intervention. J Adv Nurs 2014 Nov;70(11):2634-2650. [doi: 10.1111/jan.12413] [Medline: 25312443]

11. Viklund G, Wikblad K. Teenagers' perceptions of factors affecting decision-making competence in the management of type 1 diabetes. J Clin Nurs 2009 Dec;18(23):3262-3270. [doi: 10.1111/j.1365-2702.2009.02963.x] [Medline: 19930085]

12. Kieckhefer GM, Trahms CM. Supporting development of children with chronic conditions: from compliance toward shared management. Pediatr Nurs 2000;26(4):354-363. [Medline: 12026469]

13. Noser AE, Huffhines L, Clements MA, Patton SR. Diabetes conflict outstrips the positive impact of self-efficacy on youth adherence and glycemic control in type 1 diabetes. Pediatr Diabetes 2017 Nov;18(7):614-618. [doi: 10.1111/pedi.12471] [Medline: 27859979] 
14. Whittemore R, Liberti L, Jeon S, Chao A, Jaser SS, Grey M. Self-management as a mediator of family functioning and depressive symptoms with health outcomes in youth with type 1 diabetes. West J Nurs Res 2014 Oct;36(9):1254-1271 [FREE Full text] [doi: 10.1177/0193945913516546] [Medline: 24357648]

15. Franklin VL, Greene A, Waller A, Greene SA, Pagliari C. Patients' engagement with "Sweet Talk" - a text messaging support system for young people with diabetes. J Med Internet Res 2008;10(2):e20 [FREE Full text] [doi: 10.2196/jmir.962] [Medline: 18653444]

16. Sawyer SM, Afifi RA, Bearinger LH, Blakemore S, Dick B, Ezeh AC, et al. Adolescence: a foundation for future health. Lancet 2012 Apr 28;379(9826):1630-1640. [doi: 10.1016/S0140-6736(12)60072-5] [Medline: 22538178]

17. Holtz B, Lauckner C. Diabetes management via mobile phones: a systematic review. Telemed J E Health 2012 Apr;18(3):175-184. [doi: 10.1089/tmj.2011.0119] [Medline: 22356525]

18. Holtz BE, Murray KM, Hershey DD, Dunneback JK, Cotten SR, Holmstrom AJ, et al. Developing a patient-centered mHealth app: a tool for adolescents with type 1 diabetes and their parents. JMIR Mhealth Uhealth 2017 Apr 19;5(4):e53 [FREE Full text] [doi: 10.2196/mhealth.6654] [Medline: 28428167]

19. Griffiths F, Bryce C, Cave J, Dritsaki M, Fraser J, Hamilton K, et al. Timely digital patient-clinician communication in specialist clinical services for young people: a mixed-methods study (the LYNC study). J Med Internet Res 2017 Apr 10;19(4):e102 [FREE Full text] [doi: 10.2196/jmir.7154] [Medline: 28396301]

20. Majeed-Ariss R, Baildam E, Campbell M, Chieng A, Fallon D, Hall A, et al. Apps and adolescents: a systematic review of adolescents' use of mobile phone and tablet apps that support personal management of their chronic or long-term physical conditions. J Med Internet Res 2015 Dec 23;17(12):e287 [FREE Full text] [doi: 10.2196/jmir.5043] [Medline: 26701961]

21. Cafazzo JA, Casselman M, Hamming N, Katzman DK, Palmert MR. Design of an mHealth app for the self-management of adolescent type 1 diabetes: a pilot study. J Med Internet Res 2012;14(3):e70 [FREE Full text] [doi: 10.2196/jmir.2058] [Medline: 22564332]

22. Frøisland DH, Arsand E, Skårderud F. Improving diabetes care for young people with type 1 diabetes through visual learning on mobile phones: mixed-methods study. J Med Internet Res 2012;14(4):e111 [FREE Full text] [doi: 10.2196/jmir.2155] [Medline: 22868871]

23. Castensoe-Seidenfaden P, Husted G, Tellmann G, Hommel E, Olsen B, Kensing F. Designing a self-management app for young people with diabetes type 1 - methodological challenges, experiences and recommendations. JMIR Mhealth Uhealth 2017 Oct 23;5(10):e124. [doi: 10.2196/mhealth.8137] [Medline: 29061552]

24. Shields L, Pratt J, Hunter J. Family centred care: a review of qualitative studies. J Clin Nurs 2006 Oct;15(10):1317-1323. [doi: 10.1111/j.1365-2702.2006.01433.x] [Medline: 16968436]

25. Royal College of Nursing. 2017. Children and Young People: Transition to Adult Services URL: https://www.rcn.org.uk/ $\underline{\text { library/subject-guides/children-and-young-people-transition-to-adult-services [accessed 2018-01-15] [WebCite Cache ID }}$ 6wUT3sj1h]

26. World Health Organization. 2015. Global Standards for Quality Health Care Services for Adolescents URL: http://www. who.int/maternal child adolescent/documents/global-standards-adolescent-care/en/ [accessed 2018-01-15] [WebCite Cache ID 6wUTBXM5f]

27. Schilling LS, Grey M, Knafl KA. The concept of self-management of type 1 diabetes in children and adolescents: an evolutionary concept analysis. J Adv Nurs 2002 Jan;37(1):87-99. [Medline: 11784402]

28. Patton MQ. Qualitative Evaluation and Research Methods. 2nd. ed. Thousand Oaks: CA: SAGE Publications; 1990.

29. Anderson B, Funnell M. The Art of Empowerment: Stories and Strategies for Diabetes Educators. Arlington, Virginia, US: American Diabetes Association; 2000.

30. Denzin N, Lincoln Y. Handbook of Qualitative Research. Thousand Oaks: CA: SAGE Publications; 2000.

31. Williams G, Rodin G, Ryan R, Grolnick W, Deci E. Autonomous regulation and long-term medication adherence in adult outpatients. Health Psychol 1998;17(3):269-276. [Medline: 9619477]

32. Polonsky WH, Anderson BJ, Lohrer PA, Welch G, Jacobson AM, Aponte JE, et al. Assessment of diabetes-related distress. Diabetes Care 1995 Jun;18(6):754-760. [Medline: 7555499]

33. Braun V, Clarke V. Using thematic analysis in psychology. Qual Res Psychol 2006 Jan;3(2):77-101. [doi: 10.1191/1478088706qp063oa]

34. Graneheim UH, Lundman B. Qualitative content analysis in nursing research: concepts, procedures and measures to achieve trustworthiness. Nurse Educ Today 2004 Feb;24(2):105-112. [doi: 10.1016/j.nedt.2003.10.001] [Medline: 14769454]

35. Joensen L, Almdal T, Willaing I. Associations between patient characteristics, social relations, diabetes management, quality of life, glycaemic control and emotional burden in type 1 diabetes. Prim Care Diabetes 2016;10(1):41-50. [Medline: 26163949]

36. Joensen L, Filges T, Willaing I. Patient perspectives on peer support for adults with type 1 diabetes: a need for diabetes-specific social capital. Patient Prefer Adherence 2016;10:1443-1451. [Medline: 27536076]

37. Dennis C. Peer support within a health care context: a concept analysis. Int J Nurs Stud 2003 Mar;40(3):321-332. [Medline: 12605954] 
38. Wiley J, Westbrook M, Long J, Greenfield JR, Day RO, Braithwaite J. Diabetes education: the experiences of young adults with type 1 diabetes. Diabetes Ther 2014 Jun;5(1):299-321 [FREE Full text] [doi: 10.1007/s13300-014-0056-0] [Medline: $\underline{24519150]}$

39. Simmons D, Bunn C, Cohn S, Graffy J. What is the idea behind peer-to-peer support in diabetes? Diabetes Manag 2013 Jan;3(1):61-70. [doi: 10.2217/dmt.12.80]

40. Brownson CA, Heisler M. The role of peer support in diabetes care and self-management. Patient 2009 Mar 01;2(1):5-17. [doi: 10.2165/01312067-200902010-00002] [Medline: 22273055]

41. Mayer MK, Urlaub DM, Guzman-Corrales LM, Kowitt SD, Shea SM, Fisher EB. "They're doing something that actually no one else can do": a qualitative study of peer support and primary care integration. J Ambul Care Manage 2016;39(1):76-86. [doi: 10.1097/JAC.0000000000000079] [Medline: 26650748]

42. Due-Christensen M, Zoffmann V, Hommel E, Lau M. Can sharing experiences in groups reduce the burden of living with diabetes, regardless of glycaemic control? Diabet Med 2012;29(2):251-256. [doi: 10.1111/j.1464-5491.2011.03521.x] [Medline: 22061095]

43. Lasaite L, Dobrovolskiene R, Danyte E, Stankute I, Razanskaite-Virbickiene D, Schwitzgebel V. Diabetes distress in males and females with type 1 diabetes in adolescence and emerging adulthood. J Diabetes Complications 2016;30(8):1500-1505. [doi: 10.1016/j.jdiacomp.2016.08.013] [Medline: 27613444]

44. Fegran L, Hall EO, Uhrenfeldt L, Aagaard H, Ludvigsen MS. Adolescents' and young adults' transition experiences when transferring from paediatric to adult care: a qualitative metasynthesis. Int J Nurs Stud 2014 Jan;51(1):123-135. [doi: 10.1016/j.ijnurstu.2013.02.001] [Medline: 23490470]

45. Swallow V. An exploration of mothers' and fathers' views of their identities in chronic-kidney-disease management: parents as students? J Clin Nurs 2008 Dec;17(23):3177-3186. [doi: 10.1111/j.1365-2702.2008.02642.x] [Medline: 19012785]

46. Hardoff D, Danziger Y, Reisler G, Stoffman N, Ziv A. Minding the gap: training in adolescent medicine when formal training programmes are not available. Arch Dis Child Educ Pract Ed 2009 Oct;94(5):157-160. [doi:

10.1136/adc.2008.155762] [Medline: 19770496 ]

47. Brown T. Are you a digital native or a digital immigrant? Being client-centred in the digital era. Br J Occup Ther 2011;74(7):313. [doi: 10.4276/030802211X13099513660992]

48. Andersen T, Bansler J, Kensing F, Moll J, Nielsen K. Alignment of concerns: a design rationale for patient participation in eHealth. : IEEE Computer Society; 2014 Presented at: 47th Hawaii International Conference on System Sciences; 6-9 January, 2014; Waikoloa, HI, USA.

49. Haugstvedt A, Wentzel-Larsen T, Rokne B, Graue M. Perceived family burden and emotional distress: similarities and differences between mothers and fathers of children with type 1 diabetes in a population-based study. Pediatr Diabetes 2011 Mar;12(2):107-114. [doi: 10.1111/j.1399-5448.2010.00661.x] [Medline: 20522171]

50. Akre C, Suris J. From controlling to letting go: what are the psychosocial needs of parents of adolescents with a chronic illness? Health Educ Res 2014 Oct;29(5):764-772. [doi: 10.1093/her/cyu040] [Medline: 24997206]

51. Peeters MA, Hilberink SR, van Staa A. The road to independence: lived experiences of youth with chronic conditions and their parents compared. J Pediatr Rehabil Med 2014;7(1):33-42. [doi: 10.3233/PRM-140272] [Medline: 24919936]

52. Kowitt SD, Tang PY, Peeples M, Duni J, Peskin S, Fisher EB. Combining the high tech with the soft touch: population health management using eHealth and peer support. Popul Health Manag 2017 Feb;20(1):3-5. [doi: 10.1089/pop.2016.0027] [Medline: 27267800]

53. Rienits H, Teuss G, Bonney A. Teaching telehealth consultation skills. Clin Teach 2016 Apr;13(2):119-123. [doi: $\underline{10.1111 / \text { tct.12378] [Medline: 26016733] }}$

\section{Abbreviations}

$\mathbf{H b A}_{1 \mathbf{c}}$ : hemoglobin $\mathrm{A}_{1 \mathrm{c}}$

HCCQ: Health Care Climate Questionnaire

IT: information technology

PAID-20: Problem Areas in Diabetes

PCD: Perceived Competence in Diabetes

mHealth: mobile health

RCT: randomized controlled trial

T1DM: type 1 diabetes mellitus

YWD: Young with Diabetes 
Edited by C Dias; submitted 31.08.17; peer-reviewed by B Holtz, K Murray, M Sujan, S Stones, J McDonagh; comments to author 21.09.17; revised version received 05.10.17; accepted 05.10.17; published 28.02.18

Please cite as:

Husted GR, Weis J, Teilmann G, Castensфe-Seidenfaden P

Exploring the Influence of a Smartphone App (Young with Diabetes) on Young People's Self-Management: Qualitative Study JMIR Mhealth Uhealth 2018;6(2):e43

URL: http://mhealth.jmir.org/2018/2/e43/

doi: $10.2196 /$ mhealth. 8876

PMID: 29490897

(C) Gitte Reventlov Husted, Janne Weis, Grete Teilmann, Pernille Castensøe-Seidenfaden. Originally published in JMIR Mhealth and Uhealth (http://mhealth.jmir.org), 28.02.2018. This is an open-access article distributed under the terms of the Creative Commons Attribution License (https://creativecommons.org/licenses/by/4.0/), which permits unrestricted use, distribution, and reproduction in any medium, provided the original work, first published in JMIR mHealth and uHealth, is properly cited. The complete bibliographic information, a link to the original publication on http://mhealth.jmir.org/, as well as this copyright and license information must be included. 